\title{
DAVID C. CULVER AND TANJA PIPAN: SHALLOW SUBTERRANEAN HABITATS. ECOLOGY, EVOLUTION AND CONSERVATION
}

Oxford University Press, 2014, 1st Impression, pp. 258.

Five years after publishing their book The Biology of Caves and Other Subterranean Habitats (Oxford University Press, 2009), the Authors offer up the first modern review of the shallow, previously called superficial, subterranean habitats (SSHs). These habitats are pragmatically determined as a group of aphotic and partly twilight

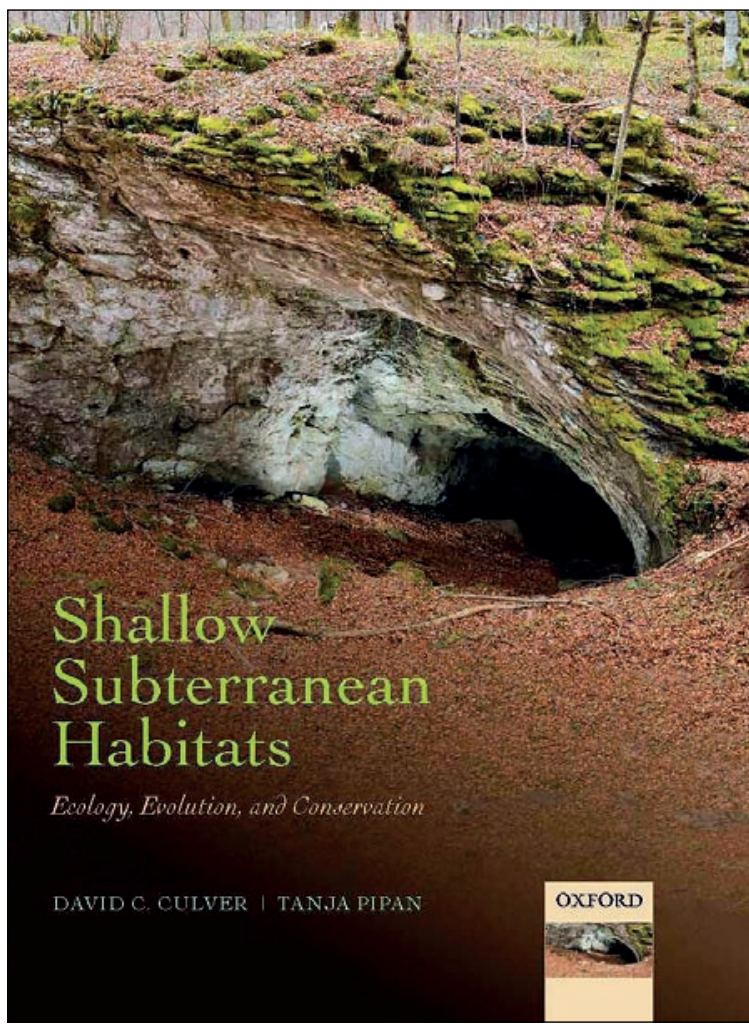
habitats down to $10 \mathrm{~m}$ below the surface. Their diameter most usually does not exceed $10 \mathrm{~cm}$, or $10 \mathrm{~m}$ in the case of lava tubes. Particular SSHs are characterized for their particular combination of the environmental circumstances and biota. The Authors distinguish between strict sense and broad sense SSHs. These include hypotelminorheic habitat with their supplying seepage springs, epikarst, shallow calcrate aquifers, intermediate-sized terrestrial and aquatic SSHs, soil and lava tubes. In the 16 chapters, the Authors discuss the SSHs referring to 550 papers and make careful conclusions. They explain that SSHs appear in either karstic regions, yielding about $15 \%$ of the earth's surface or nonkarstic areas, or in both. All these habitats interact with the surface, with the possible exception of the calcrate aquifers, and harbor, among others, the troglobiotic species.

The hypotelminorheic habitats, typically up to half a meter deep, are considered the shallowest aquatic SSHs. The epikarst, yielding about $12.5 \%$ of the earth's surface, constitutes a soil-rock interface and provides highly dynamic species distributions. The intermediate-sized terrestrial SSHs-consisted of spaces of up to about 10 $\mathrm{cm}$-are screes and taluses, milieu souterrain superficiel (MSS), shallow fissured rock and lava clinker, each of them with a specific combination of the environmental conditions. The aquatic interstitial SSHs comprise lake bottoms, hyporheic and parafluvial areas, which represent a lotic ecotone between the main water body and the ground water. The calcrate aquifers are distinctive of deserts and specific for their salinity and patchy, isolated distribution. Soils are discussed as a type of SSH, because they host a range of troglomorphic species. Lava tubes are special for their proximity with the surface and, in many of them, roots as the main source of food. Besides, short caves and any cave entrances are ecotones between 
the surface and deep subterranean habitats. The Authors exhaustively discuss similarities and differences between the treated habitats with respect to all of these features. Somehow travertine escaped the Authors' attention. This chemically-precipitated porous limestone habitat is an ecotone between surface, mostly current water, and a vadose or occasionally shallow phreatic environment (Pentecost 2005). It is known to harbor also troglomorphic taxa at least in North America (Caecidotea stygia; Pentecost 2005) and Slovenia (Iglica and Paladilhiopsis species were found by the malacologist France Velkovrh).

The Authors systematically deal with many aspects of the SSHs: their geographic distribution and morphology, variation, hydrology, geology, habitat chemical and physical characteristics and dynamics. As for fauna, they deal with ecology, and morphological characteristics of animals, species diversity, richness and distributions, principles of colonization and adaptation to the subterranean environment, convergent and divergent evolution and speciation rates, phylogeny, roles of the environmental factors (light, physical factors, organic carbon, nutrients, environmental fluctuations and stresses) on biota, circadian and annual cycles as response to environmental cyclicity, convergent and divergent selective pressures, the body and appendages size and shape in relation to (micro)habitat properties, and conservation and protection problems. The Authors expose fields of highly incomplete knowledge and appeal to research these gaps. All these are based on a variety of case studies exposing puzzling facts and terminological inconsistencies as well.

Briefly, this book is the first overall review of the shallow subterranean habitats. Information on travertine is expected if the book reprints, and one would welcome a more detailed presentation of the seashore interstitial habitats and a discussion of possible SSH ecosystem services. Three points are refreshing in the ecology and biology of the subterranean habitats: the inclusion of soils into the SSHs and the debate on troglomorphy and terminology. The Authors argue that the rotten bedrock soil horizon, i. e., the regolith, and spaces in rhizosphere are often inhabited by troglobionts. Further they explain that troglomorphic characteristics may evolve in the subterranean as well as in any other totally dark and twilight habitat, like leaf litter. Finally, they appeal to return to use a general evolutionary terminology. This book is strongly recommended to anybody, especially biologists and ecologists, dealing with any point of the aquatic or terrestrial habitats, rocks and soils down to the depth of $10 \mathrm{~m}$. And, who doesn't?

Tone Novak

Pentecost, A., 2005: Travertine.-Springer-Verlag, Berlin, Heidelberg, pp. 445. 